DOI: https//doi.org/10.13037/ci.vol22n50.8055

\title{
Comunicação em ambientes da indústria criativa: 0 contexto midiatizado de Fab Labs no Rio Grande do Sul
}

\author{
Communication in creative industry environments: the media context \\ of fab labs in Rio Grande do Sul
}

\author{
Marcela Guimarães e Silva ${ }^{\mathrm{ai}}$ \\ ORCID: https://orcid.org/0000-0002-9752-2571
}

\author{
Fabio Frá Fernandes bii \\ ORCID: http://orcid.org/0000-0003-2035-6832
}

Recebido em 25/08/2021. Aprovado em 13/10/2021.

Resumo

Nosso estudo analisa as formas como a comunicação e a mídia se integram aos ambientes da indústria criativa, ao observar os diferentes fenômenos que a mediação tecnológica produz em Fabrication Laboratories (Fab Labs). Operacionalizada pelo método exploratório-descritivo-explicativo e aplicado em seis laboratórios localizados no estado brasileiro do Rio Grande do Sul, constata-se que a comunicação se integra em tais ambientes a partir de projetos, práticas e profissionais da comunicação. Formas de atuação processualizadas pela Comunicação Organizacional Midiatizada que, ademais, articula os campos semânticos da veiculação, vinculação e cognição (SODRÉ, 2012) para constituir um quarto bios existencial que contribui com a estruturação de Fab Labs, nomeadamente, ambientes da indústria criativa.

Palavras-chave: Midiatização. Indústria Criativa. Ambientes de Inovação. Fab Lab.

\begin{abstract}
Our study analyzes the ways in which communication and media are integrated into creative industry environments, by observing the different phenomena that technological mediation produces in Fabrication Laboratories (Fab Labs). Operated by the exploratorydescriptive-explanatory method and applied in six laboratories located in the Brazilian state of Rio Grande do Sul, it appears that communication is integrated in such environments through projects, practices and communication professionals. Forms of action processed by Mediatized Organizational Communication which, moreover, articulates the semantic fields of dissemination, bonding and cognition (SODRÉ, 2012) to constitute a fourth existential bios that contributes to the structuring of Fab Labs, namely, environments of the creative industry.
\end{abstract}

Keywords: Mediatization. Creative Industry. Innovation Environments. Fab Lab.

\footnotetext{
${ }^{\text {a } U n i v e r s i d a d e ~ F e d e r a l ~ d o ~ P a m p a ~(U n i p a m p a), ~ c a m p u s ~ S a ̃ o ~ B o r j a . ~ R i o ~ G r a n d e ~ d o ~ S u l / B r a s i l . ~ E-m a i l: ~}$ marcelasilva@unipampa.edu.br

${ }^{\mathrm{b}}$ Universidade Federal de Santa Maria (UFSM). Rio Grande do Sul/Brasil. E-mail:

fabio.fra.fernandes@outlook.com
} 


\section{Introdução}

É lugar-comum afirmar que as tecnologias, em especial aquelas relacionadas à comunicação e informação, alteraram paradigmas sócio-organizacionais. A já tão conhecida sociedade da informação e em rede, com suas tecnologias digitais, impõem com intensidade variada, seus sempre atualizados componentes a práxis da sociabilidade contemporânea.

A mídia, e toda sua trajetória histórica, ocupa posição de destaque nesse contexto. Suas lógicas e affordances são apropriadas por indivíduos e organizações para estender sentidos e operar na forma de mediação, de técnica ajustada para efetivar a comunicação e, por extensão, as interações sócio-organizacionais que nesse contexto tornam-se profundamente midiatizadas.

O fenômeno da indústria criativa situa e posiciona diferentes setores de uma economia baseada na interlocução entre criatividade, cultura, inovação e tecnologia. A mídia e as comunicações como extensões sócio-organizacionais, sob a perspectiva da midiatização, são postas por nós, como lentes-reflexivas para investigar ambientes inseridos nos setores da indústria criativa. Na forma de organizações, tais ambientes se apresentam como disruptivos, baseados no trabalho colaborativo e na economia do compartilhamento. Dessarte, os ambientes da indústria criativa, ressignificam os modelos organizacionais a partir do reflexo e das inferências que o desenvolvimento da mídia ocasiona em seu modus operandi.

É da inter-relação entre as transformações na mídia, na comunicação, na cultura e na sociedade, que analisamos a realidade de seis Fabrication Laboratories (Fab Labs), localizados no estado brasileiro do Rio Grande do Sul, organizações entendidas por nós, como ambientes multissetoriais da indústria criativa. Interessa-nos com tal análise, problematizar as formas com que a mídia e a comunicação se integram aos ambientes da indústria criativa. Para tanto, pelo método exploratório-descritivo-explicativo, à luz da teoria da midiatização, investigamos as relações que a mídia e a comunicação têm com os ambientes da indústria criativa, ao passo de descrever os processos e práticas comunicacionais ali desenvolvidas. Ademais, ainda verificamos a presença de profissionais de comunicação e as nuances de sua participação frente às inúmeras possibilidades de trabalho que os Fab Labs oferecem. 
2 Comunicação, tecnologia e sociabilidade: da mídia à midiatização da sociedade e suas organizações

Com um breve retrospecto sobre a trajetória histórica da mídia e da comunicação, especificamente nos últimos seiscentos anos, é possível vislumbrar com clareza que a sociabilidade, em maior ou menor grau, tem tornado-se mediada por diferentes organismos de mídia. Situação que se aprofunda, frente à qualificação dos diferentes organismos de mídia, a notar, nos últimos dez anos, quando a inter-relação e interdependência de indivíduos, sociedades e organizações, com o ecossistema midiático, tem se tornado algo naturalizado. Tal inter-relação e interdependência são nomeadas no âmbito das Ciências Sociais, especificamente no campo da Comunicação, como fenômeno da midiatização. Entendido como um meta-processo, ou metadisciplina, a midiatização busca compreender as mudanças sociais perpassadas pela mídia (COULDRY; HEPP, 2020). É um fenômeno que decorre da tecnointeração, o que significa as variadas faces da interação entre pessoas, organizações com as tecnologias de mídia. Os processos midiatizados traduzem a realidade da sociabilidade tecnológica, algo que sempre existiu por meio da mídia tradicional e de mercado, mas que no contemporâneo se consolida com as novas propriedades da técnica digital de comunicação e relacionamento.

Partindo do pensamento de McLuhan (1964), junto a outros ecólogos da mídia (POSTMAN, 2000; CANAVILHAS, 2020; STRATE; BRAGA; LEVINSON, 2019; BARICHELLO, 2017) e pesquisadores da midiatização (SODRÉ, 2012; HJARVARD, 2014; COULDRY; HEPP, 2020; GOMES; 2017), significamos mídia como tecnologia. Isso, por entendermos a mídia de base tecnológica, como um direcionador das diferentes faces da sociabilidade, com ideologias, lógicas e visões de mundo específicas. Significação que parte também, do contexto sociotécnico onde existe uma mútua afetação entre as possibilidades tecnológicas e o fazer humano.

Conceitualmente, mídia é proveniente do Latim media, plural de medium, e denota meios, mas este no sentido de meios de comunicação. Não se trata essa conceituação, portanto, dos meios de comunicação como mero canal, mas sim pelo conjunto de meios representados tanto pelas instituições sociais dotadas de valores, normas e regras, como das tecnologias e suas affordances. É a mídia, assim, um ambiente, muito além de suportes técnicos, mas “com interações tecnossociais, apropriações simbólicas, questões organizacionais e culturais" (BARICHELLO; CARVALHO, 2013, p. 237). 
A mídia tem lógicas próprias para seu funcionamento, mas na sociedade midiatizada, essas mesmas lógicas são apropriadas pelos indivíduos e organizações que ressignificam seus usos, regras e valores. Como bem definem Barichello et al. (2013, p. 132), “as lógicas que organizam o funcionamento de domínios específicos da experiência humana, são afetados pela lógica da mídia e passam a ser constituintes de uma nova ambiência midiatizada".

Nesse estágio de evolução tecnossocial, a mídia se desloca como campo específico de mediação, para se tornar ambiência e, assim, perpassar todos os campos da experiência humana. Todas as questões tecnológicas que a tangenciam, acabam por representar efeitos específicos, mas convergentes sobre sua apropriação e usabilidade. Seja no âmbito das técnicas ou na produção de sentido, maiores e mais importantes que o artefato midiático-tecnológico em si, ou seu conteúdo, está a transformação que essa articulação ocasiona. Ou seja, cada parte - a mídia, o suporte, o conteúdo, o interagente - é corresponsável pelos efeitos nos processos de interação e comunicação mediada (DALL'AGNESE; BARICHELLO, 2018).

Sobre isso, Sodré (2012) com sua concepção de bios midiático colabora com a compreensão da midiatização, ao explicar com esse conceito, as transformações nas formas tradicionais de sociabilização. Para o autor, o bios midiático é concebido das mudanças nas perspectivas de relacionamento entre indivíduos e entre organizações que, com o constante e acelerado desenvolvimento tecnológico, acaba por implicar em novas ou renovadas formas de se perceber, refletir e praticar comunicação. Em síntese, o autor entende a existência de três bios existenciais a partir do pensamento de Platão e de Aristóteles. Cada bios representa um gênero qualificativo onde se desenrola a existência humana. O bios midiático seria o quarto bios, a quarta esfera existencial, onde a midiatização é pensada como tecnologia de sociabilidade, e predomina a esfera dos negócios, dotada de uma qualificação cultural própria, a tecnocultura. Esse quarto bios é o território da mídia (SODRÉ, 2012), possível de ser entendido pela infraestrutura e pelos organismos de mídia que formam o ecossistema comunicacional midiatizado.

No bios midiático, pelo inesgotável fluxo de informações, os indivíduos que o acessam nunca saem dele com a mesma perspectiva, mas sim modificados. Esse processo também acontece sobre a sociedade e suas organizações, pois, um indivíduo que sofre transformações ao acessar o bios midiático vai, sequencialmente, transformar outros conforme sua esfera de relações sociais e organizacionais. 
Ao articular as tecnologias com os processos de comunicação para conceituar o bios midiático, Sodré (2012) descreve três campos semânticos que ajudam a sua compreensão, ao passo de também visualizar as práticas comunicacionais e midiáticas de indivíduos e das organizações: veiculação, vinculação e cognição, são os campos semânticos que posicionam a reflexão, esclarecem e caracterizam as práticas de comunicação e interação nesse quarto bios.

Em síntese, entendemos a veiculação pelas estratégias midiáticas empregadas e institucionalizadas para informar e gerar comunicação. Pode ser traduzida enquanto o meio (mídia) em si. A vinculação, por sua vez, trata de articulações para gerar e gestar os nós que dão forma à rede sociotécnica de comunicação, ou seja, refere-se aos ligamentos, aos vínculos sociais mantidos e estabelecidos por indivíduos, sociedades e organizações. Ademais, é a vinculação objetivada pelas reações ao campo da mídia. Logo, a cognição vai tratar do significado, da posição reflexiva que tanto o indivíduo, a sociedade e suas organizações, têm sobre a articulação entre veiculação e vinculação.

Os campos semânticos da midiatização propostos por Sodré, de modo pragmático, podem ser melhor visualizados quando observados os processos e práticas de comunicação organizacional. Em que os ambientes midiatizados criam, não somente novos fluxos e redes de comunicação e interação, mas acabam por potencializar novos arranjos, formatos funcionais e estruturais para as organizações. Criam-se, também, novas mediações e interlocuções (veiculação) entre as organizações, indivíduos e sociedade, nas quais tal ambiência torna-se peça fundamental para formar conexões (vinculações), ampliar sua visibilidade e tornar legítima sua atuação (cognição).

Ao observarmos a trajetória histórica da comunicação organizacional no contexto da midiatização (KUNCSH, 2016; BARICHELLO, 2017), especialmente nos últimos anos, percebemos a emergência de atores sociais mais partícipes que, apropriados da mídia, passam a influenciar e ressignificar a cultura das organizações. Em outras palavras, os ambientes midiáticos contribuem com o aumento da participação social e organizacional desses atores, quando possibilita a relação dialógica e aproximativa dos atores internos e externos às organizações (FERNANDES; SILVA, 2020).

$\mathrm{Na}$ atualidade, a comunicação e a mídia se apresentam como um emaranhado de nós, matematicamente configuradas e ajustadas para tornar suas tecnologias, ambiências midiáticas tão densas, que tantos os atores sociais, quanto os organizacionais, não percebem o quão profundo são suas lógicas e operações em seu cotidiano. Todos os 
âmbitos da comunicação organizacional - interna, administrativa, mercadológica e institucional - passam a sofrer com as inferências dos processos midiatizados.

\section{Ambientes da Indústria Criativa: Fab Labs enquanto organizações para inovação e tecnologia}

Um ambiente da indústria criativa é, para nós, significado como um conjunto de estruturas relacionadas com as infraestruturas endógenas de um lado, e pelos indivíduos que dele fazem parte, uso e, ainda, com arranjos sócio-organizacionais exógenos. Apresentam-se na forma de organizações que do alargamento tecnológico passar a ser configuradas em novos modelos e arranjos negociais, geralmente conectados em rede, onde seu principal insumo de trabalho é centrado na inovação e na criatividade. É, também, característica fundante desses ambientes sua estreita relação com os setores que dão forma à economia criativa.

Enquanto fenômeno sistêmico, o agente e os atores interagem com o seu meio e sistematizam processos que objetivam a produção de novos produtos, tecnologias ou soluções (MATOS; TEIXEIRA, 2019). Um ambiente da indústria criativa preconiza assim, o processo inventivo, a sociabilização, a colaboração e o compartilhamento de experiências. Para mais, as interações efetivadas em ambientes da indústria criativa, tendem a extrapolar seu meio. Sendo assim, são estabelecidos vínculos endógenos (indivíduos em situação de proximidade organizacional) e exógenos (agentes e atores externos, com relação a outras organizações criativas).

O principal objetivo de um ambiente da indústria criativa encontra-se na criação de movimentos de mudança, em que realidades são transformadas por meio de dinâmicas de cooperação, ao envolver indivíduos distintos, dispostos com objetivos comuns, mas que interagem entre si e sofrem ações destas interações. A cultura maker (ANDERSON, 2012) e o movimento coworking (JACKSON, 2013), são algumas das referências para a constituição de tais ambientes, visto que suas características principais estão circunscritas na capacidade de as pessoas articularem seus recursos, formar redes para cocriação, desenvolver produtos, serviços em espaços compartilhados e em colaboração.

Em tais ambientes, estão as mídias posicionadas no núcleo de sua constituição. Os indivíduos, de modo articulado, utilizam dessas tecnologias para configurar espaços que podem ser físicos ou virtualizados, para o trabalho criativo, inventivo e colaborativo. Emerge dessa configuração, ambientes organizacionais que buscam menos linearidade 
em suas atividades-meio e fim, diminuem as regras e a burocracia, bem como otimizam o tempo, espaço, e ampliam as conexões em rede para que o conhecimento ali gerado possa alcançar o maior número de pessoas ou beneficiários possíveis. Sua configuração, para isso, pode acontecer a partir de agentes públicos e privados, ou, ainda por iniciativa de indivíduos isolados, mas conectados por diferentes mídias.

Podemos destacar diferentes ambientes a partir dessas características, sejam eles mais centrados na inovação e tecnologia - parques científicos e tecnológicos, centros de inovação, incubadoras, aceleradoras, startups (TEIXEIRA et al., 2016) -, ou pelo grau de colaboração e desburocratização de suas práticas - coworking spaces (JACKSON, 2013) - e os Fabrication Laboratories (Fab Labs). Essas identificações variam conforme os agentes que propõem sua organização: empreendedores criativos, agências governamentais, instituições de ensino e pesquisa, grupos comunitários. São esses proponentes, sua cultura organizacional e demais práticas negociais que determinaram também, o perfil dos usuários, formas de relacionamento e interação ou, ainda, se o modelo de negócio adotado tenderá para métodos inovativos ou tradicionais. Não obstante, o que mantêm essas identificações relacionadas com nossa concepção de ambiente da indústria criativa, são os vínculos possibilitados pelo digital, onde os diferentes aparatos técnicos estendem seu campo e alcance comunicacional (veiculação) e, ademais, sobre a significação (cognição) dos efeitos que os ambientes midiáticos demandam para o entorno.

Aos Fab Labs, no que lhes concerne, caracterizam-se enquanto organizações baseadas na identificação de problemas possíveis de solução por meio da prototipação digital, ou seja, ambientes para inovação e tecnologia. Sua constituição parte da adoção de uma série de orientações e de metodologias específicas definidas pela Fab Foundation, uma organização sem fins lucrativos, criada em 2009 junto ao Center for Bits and Atoms (CBA) do Massachusetts Institute of Technology (MIT).

A lógica do trabalho em um Fab Lab segue a ideia de redes de compartilhamento e de produção de conhecimento (SILVEIRA; SILVA, 2018). Os processos e as técnicas utilizadas em todos os projetos precisam ser disponibilizados a outros usuários da rede, de modo a permitir que a inovação alcance o maior número de pessoas possíveis. É também prerrogativa dos laboratórios, garantir que o conhecimento e as experiências ali construídos sejam compartilhados, em um processo de descoberta, adoção e inspiração.

Muitas podem ser as formas de organização adotadas pelos Fab Labs. Nos casos mais comuns, existe "uma organização mãe, uma estrutura associativa, uma fundação, 
uma universidade, um programa governamental" que estruturam e financiam esses ambientes. "A organização ou organizações que financiam um Fab Lab possuem papel determinado na definição do mesmo (usos, usuários, modelos de gestão e de organização)" (EYCHENNE; NEVES, 2013, p.17). É possível, segundo as autoras, desenhar três categorias de Fab Labs, sendo eles os modelos: acadêmico, profissional ou público.

\section{Percurso metodológico}

A partir do pensamento de Barichello (2016, p.131), entendemos que trabalho de pesquisa precisa contribuir para o campo e fenômeno estudado a partir da "descoberta de fatos novos ou, ainda, ao demonstrar a aplicação de uma criteriosa e coerente crítica aos conceitos que circundam o núcleo de sua temática". É a partir dessa compreensão que empreendemos o método exploratório-descritivo-explicativo, visto que cada possibilidade de ação na operacionalização de procedimentos e técnicas, no que tangencia o método em questão, nos permite extrair, tanto do campo (mídia e comunicação), quanto do objeto (ambientes da indústria criativa na forma de Fab Labs), as respostas para esse estudo.

Por meio da triangulação entre levantamento bibliográfico, análise documental e entrevistas com observação, coletamos dados e informações em três etapas executadas de forma não linear. A pesquisa de campo foi realizada em 2019, quando acessamos seis Fab Labs localizados no estado brasileiro do Rio Grande do Sul, ativos conforme informado pela Fab Foundation. Dessarte, o objeto empírico da nossa pesquisa constituiu-se por cinco laboratórios domiciliados no município de Porto Alegre, capital do estado, e um, no município de Canoas, região metropolitana. 


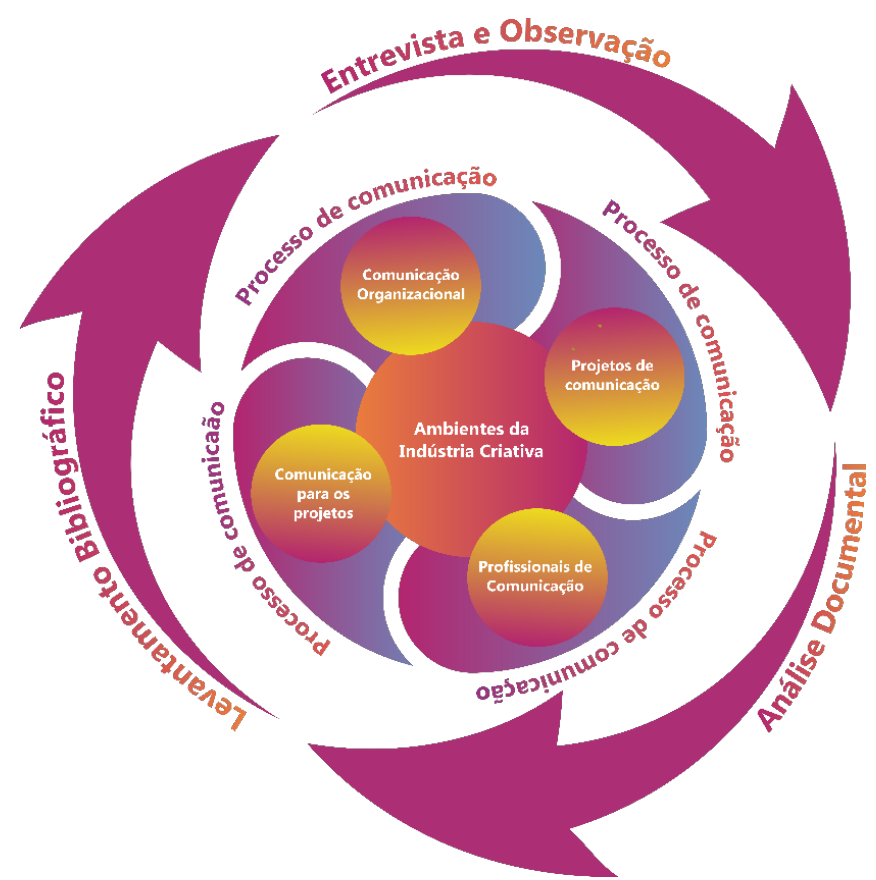

Figura 1 - Triangulação metodológica e análise do processo de comunicação nos Fab Labs no Rio Grande do Sul

Fonte: elaborada pelos autores.

Com o levantamento bibliográfico, exploramos bases conceituais e analíticas sobre a problemática em questão. Complementarmente, as análises de documentos permitiram identificar informações relacionadas com a constituição dos Fab Labs investigados, sobre sua realidade comunicacional e midiática. As principais fontes para ambos os procedimentos foram: portais institucionais, redes sociais digitais, políticas institucionais, relatórios, cartilhas, materiais promocionais de divulgação, bem como os seus projetos ativos e inativos.

As entrevistas foram realizadas com os fab-managers ${ }^{3}$ de cada laboratório, conduzidas de forma presencial e organizadas em questionários semiestruturados. Os principais tópicos articulados buscaram ampliar nosso entendimento sobre a rede $\mathrm{Fab}$ $L a b$, e sua dispersão diante de questões transnacionais e multiculturais. Buscamos conhecer, também, a partir da especificidade da amostra, o histórico, modelo, estrutura organizacional, objetivo estratégico, público-usuário, parcerias firmadas com outras organizações e, principalmente, sobre as tecnologias disponíveis para operacionalizar seus processos e práticas de comunicação.

\footnotetext{
${ }^{3}$ Nomenclatura utilizada para representar o profissional responsável pela gestão e organização tanto do laboratório, quanto dos seus usuários e projetos.
} 
No âmbito das comunicações e da mídia, buscamos perceber o processo de comunicação organizacional, bem como técnicas e instrumentos utilizados para a manutenção da sociabilidade entre os laboratórios, seus públicos de interesse, organizações parceiras, órgão de fomentos, e com a Fab Foundation. Ademais, observamos a presença de profissionais de comunicação enquanto indivíduos com vínculo direto aos Fab Labs (emprego formal ou terceirizado), ou sem vínculo, realizando projetos próprios de comunicação, utilizando dos recursos dos laboratórios para prototipar bens e serviços comunicacionais. Por fim, a observação, complementou a coleta de dados e informações das demais técnicas e procedimentos.

\section{Comunicação para a Indústria Criativa: a midiatização como ambiência inovativa nos Fab Labs gaúchos}

Até aqui fica claro que os ambientes da indústria criativa são, também, organizações. São formados por estruturas planejadas com objetivos, metas e estratégias para seu funcionamento, desenvolvimento, legitimação e visibilidade. Como visto, a partir do exemplo empírico dos $F a b L a b s$, a comunicação e a mídia têm posição nuclear sobre seu desenvolvimento. Diante das especificidades relacionais, de interação e de comunicação organizacional, presentes no agrupamento planejado e ordenado de pessoas que trabalham conjuntamente para atingir objetivos comuns, acabam por formar estruturas de significados sócio-organizacionais. Situação que explicita as inferências do fenômeno da midiatização, principalmente ao percebemos os processos de vinculação, veiculação e cognição desses ambientes na perspectiva do bios midiático.

De acordo com Teixeira et al. (2016), três elementos são fundamentais para estruturar e compreender os ambientes interseccionados pelos campos inovativos e criativos, sendo eles: conhecimento, empreendedorismo e inovação. Inserimos nessa composição, um quarto elemento: a comunicação.

O conhecimento ocupa hoje, na economia mundial, lugar de destaque. Estando ele no centro das estratégias para todo e qualquer tipo de desenvolvimento. Castells (2016), ao conceituar sociedade da informação e em rede, já colocava o conhecimento e o compartilhamento de informações, no cerne da produção industrial e das relações comerciais da modernidade. Os ambientes da indústria criativa, nessa perspectiva, têm como pressuposto a articulação eficiente dos ativos provenientes do conhecimento, pelo 
compartilhamento de informações, pela função de propagar, ampliar a visibilidade e o acesso às atividades relacionadas à inovação e transferência de tecnologia.

Da produção e compartilhamento do conhecimento, os ambientes da indústria criativa também passam a ser usados para formar uma cultura empreendedora, onde os indivíduos são estimulados a desenvolver novas organizações, experiências e tornar as tecnologias geradas na articulação criatividade-inovação, ativos sociais, culturais e econômicos.

A comunicação, como quarto elemento estrutural dos ambientes da indústria criativa é, assim, posta para entender os sistemas, fluxos, redes e transformações na sociedade e na cultura que a midiatização demanda aos indivíduos e organizações. Com a mídia, é possível não somente ampliar as conexões para trocas simbólicas entre os diversos interagentes no âmbito da indústria criativa, mas sim, convidá-los a participar dos processos constitutivos de seus ambientes. Por essa razão, para difundir a criatividade e a inovação, desenvolver a cultura do empreendedorismo, produzir e compartilhar conhecimento, um ambiente da indústria criativa vai precisar de processos de comunicação que serão organizados para garantir os fluxos, materializar instrumentos, técnicas comunicacionais e relacionais. Portanto, a comunicação e seu ecossistema midiático, nesse contexto, são considerados um elemento de unificação entre os demais. Ao nosso entendimento, seria a comunicação, na perspectiva da midiatização, um quarto bios estrutural dos ambientes da indústria criativa, talvez com certa semelhança ao bios midiático proposto por Sodré.

É preciso destacar que, na perspectiva organizacional, a comunicação e o campo da mídia, tornam possíveis os processos interacionais, a significação e as interpretações que sustentam o fazer de um ambiente da indústria criativa. A processualidade da comunicação no contexto das organizações é esquematizada enquanto um sistema complexo, que integra a produção de expressões e o recebimento de impressões. Um sistema que além de organizar as estratégias e usos diversos da mídia, ainda dá sentido ético e estético para as materialidades comunicativas no contexto das organizações (FERNANDES; SILVA, 2020).

Tem também a comunicação, no contexto das organizações, a missão de melhor desenvolver, qualificar e explorar o ecossistema midiático disponível para o relacionamento e para as comunicações com seus públicos, outras organizações e instituições. Essa articulação é mais um indicativo que colabora com a posição da comunicação enquanto quarto bios estrutural de um ambiente da indústria criativa, junto 
ao conhecimento, a inovação e o empreendedorismo. Visto que nesses ambientes (organizações), as configurações e estratégias midiáticas, se formam pelos diferentes aparatos tecnológicos (mídia) da ambiência comunicacional relacional (midiatização). Nessa abordagem, a mídia é o lugar simbólico ancorado pelos complexos sistemas interacionais entre os ambientes e seus públicos, ou seja, a midiatização passa a ser configurada como uma ambiência inovativa nos Fab Labs, por exemplo.

Ao triangularmos os procedimentos e técnicas de pesquisa indicados para o presente estudo, e acessarmos os Fab Labs do Rio Grande do Sul, podemos perceber a midiatização pelas práticas de veiculação, de vinculação e de cognição que, sistematicamente, transformam a sociabilidade ali possibilitada. Tendo nas questões sociotécnicas o primado de sua constituição, um $F a b$ Lab oferece mudanças nas perspectivas relacionais, de trabalho, de comunicação e, por extensão, nos processos de transferência tecnológica.

Sendo os campos semânticos da midiatização catalisadores para formar o bios midiático, por simetria ao nosso quarto bios estrutural de um ambiente da indústria criativa, é certo que um indivíduo, ao acessar um Fab Lab, passará a refletir as transformações proporcionadas pela midiatização. Tal reflexo acomete não apenas sobre os modelos de produção e de trabalho que tem no digital, novas possibilidades (cognição), mas também sobre as questões de vínculo com pessoas ali posicionadas ou, digitalmente localizadas. As ações de veiculação também passam a interferir no compartilhamento e na publicização daquilo que o indivíduo produz em tais ambientes.

Do processo de midiatização, percebemos as práticas de veiculação nos Fab Labs pelos aparelhos e suportes midiáticos por eles utilizados para efetivar suas estratégias de comunicação organizacional. São técnicas e procedimentos já institucionalizados, seja pela cultura da organização que dá suporte ao laboratório, no caso dos modelos acadêmicos, ou pelos padrões sócio-organizacionais no seu entorno, situação principal sobre modelos privados.

Muitas das práticas de veiculação seguem, ali, padrões midiáticos, ao utilizarem equipamentos comuns a várias organizações como manuais, boletins informativos impressos, ou murais. Novos suportes de mídia como as redes sociais ou aplicativos para troca de mensagens, são apropriados para o serviço da comunicação administrativa, interna, institucional ou mercadológica. Pelas características desses ambientes e dos seus usuários, outras formas de comunicação organizacional também são pensadas e instauradas para efetivar suas estratégias de comunicação e relacionamento. 
Situação explicada, por estarem esses ambientes, inseridos em contextos de organizações maiores e mais antigas, com processos engessados que transferem muitas vezes as características de sua cultura organizacional para os gestores e indivíduos que se ocupam das organizações criativas. Muitos dos Fab Labs estão iniciando a transição de um modelo formal para um modelo mais informal no que tange às práticas de gestão e de comunicação. Situação que determina apropriação de outras tecnologias, bem como a flexibilização de fluxos informacionais internos e externos. Para mais, ainda possibilitam o uso e apropriação de outras tecnologias, outros modelos relacionais para sua comunicação organizacional.

No POALAB, exemplos da prática da veiculação configuram-se no uso de suportes analógicos e digitais. De acordo com seu fab-manager, as características comunicacionais do Fab Lab são pautadas pela gestão do Instituto Federal do Rio Grande do Sul, sua mantenedora. Murais e portal institucional são as mídias de maior usabilidade para a prática da comunicação do laboratório, seguido de sua página no Facebook. Não obstante, no LIFELAB, as estratégias comunicacionais são meramente informativas, centradas em seu Portal Institucional, única mídia desdobrada pelo laboratório. No Fablab-Unilasalle, ao que lhe concerne, a prática de veiculação acontece pela institucionalização do Facebook como meio oficial do laboratório. Essa prática é muito maior no Fablab-UnisinosPOA, que midiatiza sua comunicação de imprensa, usa organismos de mídia digital e analógicas sendo, muitas vezes, desenvolvida e prototipada pelo próprio laboratório. Processo semelhante ao experienciado no TECNOPUC-Fablab, em que as práticas veiculativas são profundamente digitais e tecnológicas. Nele, as mídias analógicas estão quase que totalmente em desuso.

Sobre as práticas de vinculação, é visível em nossa amostra a configuração de outras estratégias de comunicação midiática, de modo a romper com o que é posto pela institucionalidade de suas mantenedoras. Exemplos disso são as formações de grupos de discussões em sites de redes sociais e grupos em aplicativos para troca de mensagens, como o WhatsApp, Facetime e Facebook Messenger. Essa é uma prática percebida em todos os ambientes, mas no Usina Fablab, são essas mídias os principais instrumentos de vínculo entre os sócios do laboratório e demais interagentes, diante de uma usabilidade que extrapola os atos e efeitos da conversa, e torna os aplicativos recurso para memória digital. Reduto para compartilhamento de conteúdo, ou mesmo como mural para lembretes e afins. Conforme os sócios do laboratório, foi pela emergência dos 
comunicadores instantâneos, dos sites e aplicativos de redes sociais, que os primeiros passos para a constituição do Usina Fablab foram dados.

É importante destacar que, em nossa compreensão, o uso do WhatsApp é considerado uma prática de vinculação, a priori, pelas formações afetivas e sociais possibilitadas por suas affordances. A posteriori, também pode ser percebido como práticas de veiculação diante de sua apropriação cada vez mais comum por organizações e indivíduos como suporte de mídia e instrumento para a comunicação organizacional.

Com o uso de aplicativos como o WhatsApp, podemos perceber outra forma de alteração nos fluxos de comunicação e informação, já que são aplicações que fogem do controle das organizações, o que nos modelos tradicionais de comunicação era comum. Com a midiatização da sociedade, isso começa a ser reconfigurado. Questão significativa referente aos ambientes da indústria criativa, diante do distanciamento ou da reconfiguração dos modelos tradicionais de comunicação e, consequentemente, das formas de controle comunicacional e organizacional.

$\mathrm{Na}$ vinculação ainda estão presentes os encontros e os eventos onde, tanto os usuários, quanto os gestores dos Fab Labs constroem laços afetivos e sociais, que podem convergir, futuramente, em laços de trabalho. A conjugação do digital oportuniza muitos desses encontros que são fisicamente inexistentes. A própria ideia de compartilhamento da Fab Foundation é regida por trocas no digital. O vínculo entre os makers, entre os Fab Labs e seus projetos, tem a prerrogativa de se formarem a partir das características sociotécnicas e da tecnointeração. Como exemplo, no Fablab-UnisinosPOA, os makers compartilham em suas redes de relacionamento quais projetos estão desenvolvendo no laboratório. Simultaneamente, interessados ou admiradores da ideia interagem com o produtor, formando outra rede de cooperação. Para o fab-manager do POALAB, é esse comportamento que amplia as conexões entre os Fab Labs com outras áreas do conhecimento, outros modelos de organização e outras formas de fomento à cultura maker e ao movimento coworking.

Pela cognição, estão inscritos nos Fab Labs a reflexão sobre a necessidade de repensar práticas e processos. A cultura do compartilhamento, a cultura maker e o próprio movimento coworking instigam como os indivíduos se percebem no universo que fazem parte e, ao se deslocarem entre tais movimentos, passam a transformar a si mesmos e aos que se encontram em seu entorno.

$\mathrm{O}$ arraigamento de práticas organizacionais, comunicacionais e midiáticas em modelos engessados e distantes da midiatização, faz com que os indivíduos (que já 
possuem sua sociabilidade midiatizada) buscarem outros espaços, ou seja, ambientes mais abertos e flexíveis, que permitam a efetivação de novas práticas e novos processos. Nos Fab Labs, essa realidade é percebida ao passo que em algumas universidades e institutos educacionais que os mantêm, o uso de laboratórios para pesquisa e prototipação são limitados, seguem regras e padrões rígidos. Exemplo que tanto os fab-managers do POALAB, Fablab-UnisinosPOA, Fablab-Unilasalle e TECNOPUC-Fablab, afirmam ser comportamentos comuns nas organizações aos quais seus laboratórios estão subordinados. Não obstante, por serem processos consideravelmente novos - alguns desses Fab Labs tem menos de cinco anos - os movimentos de mudança já estão em curso, e passam a ressignificar processos e práticas educacionais, experimentais, tanto em nível de graduação, quanto de pós-graduação.

Por compartilharem da ideia de flexibilidade, de permitir que seus usuários realizem com suas próprias mãos seu projeto e com certa autonomia em todo o processo de sua constituição, os Fab Labs quebram com muitos dos paradigmas institucionais. Essa quebra, quando chega ao conhecimento do indivíduo criativo (aluno, professor, cientista, pesquisador, maker), com desejo pela inovação, automaticamente vai deslocar seu esforço dos laboratórios burocráticos para os laboratórios abertos.

Dos vínculos constituídos da cultura maker ou do movimento coworking, da ascensão da ideia de uma classe criativa ${ }^{4}$, tais ambientes se consolidam nas instituições de ensino superior como porta de entrada para repensar as práticas e os processos educacionais. Situação semelhante sobre os Fab Labs estudados nesta pesquisa, onde podemos perceber nessas trocas, a prática da cognição para um repensar organizacional, materializado em modelos de ambientes da indústria criativa.

Para sintetizar as práticas de vinculação, veiculação e cognição dos Fab Labs do Rio Grande do Sul, a partir de seu bios midiático e estrutural, apresentamos um quadro em que destacamos de que forma a comunicação participa e se integra a esses ambientes da indústria criativa.

\section{COMUNICAÇÃO NOS AMBIENTES DE INDÚSTRIA CRIATIVA}

LABORATÓRIOS
Projetos de comunicação
Comunicação para projetos
Profissionais de comunicação

${ }^{4}$ Ver mais em Florida, 2011. 
Fablab-

UnisinosPOA

LIFELAB

Usina-Fablab

POALab

TECNOPUC-Fablab de digitalização e virtualização nos processos e práticas sócioorganizacionais e comunicacionais. em totalidade digitais, apropriados de comunicacores instantâneos, sites, aplicativos e redes sociais.

Aqui, os organismos de mídia analógico e digital, são interseccionados para dar vasão aos seus processos comunicativos. Murais, informativos impressos, catálagos, sites, aplicativos e redes sociais são alguns exemplos.

Não há registros.

Não há

registros.

Não há registros.

De modo incial, há projetos nas áreas de relações públicas, publicidade e propaganda, fotografia e audiovisual.

Desde sua fundação, estudantes e profissionais de comunicação de todas as áreas, com mais vasão aos publicitários e relaçoespúblicas, desenvolvem projetos de comunicação.
Ainda

embrionário, alguns

estudantes

colaboram com

projetos

desenvolvidos

no Fab Lab.

Destaque para às áreas de relações públicas, publicidade e fotografia.

Não há registros.

Não dispõe de profissionais, mas faz usos das estruturas comunicativas da Universidade.

Não há registros. Não há registros.

Não há registros.

Não dispõe de profissionais, mas faz usos das estruturas comunicativas da Universidade.

De modo colaborativo, os estudantes e profissionais de comunicação que desenvolvem seus projetos no laboratório, colaboram com o

desenvolvimento de outros projetos. Existe também, em projetos maiores e mais consolidados, profissionais atuando especificamente para eles.
Possui bolsitas de comunicação, bem como proporciona a colaboração entre os profissionais que do laboratório faz uso, para contribuir com suas estratégias comunicacionais. 


\author{
A comunicação organizacional aqui, \\ se processualiza basicamente por meio \\ da mídia digital. Sites, aplicativos e \\ redes sociais, operacionalizam suas \\ Fablab-Unilasalle \\ estratégias institucionais, \\ mercadológicas, internas e \\ adminsitrativas. No analógico, apenas \\ Não há Não há registros. \\ Não dispõe de \\ profissionais, mas \\ registros. \\ faz usos das \\ estruturas \\ comunicativas da \\ eventos e brindes são desenvolvidos. \\ Universidade. \\ Quadro 1 - Síntese do processo comunicacional nos Fab Labs do RS \\ Fonte: elaborado pelos autores.
}

\title{
6 Considerações Finais
}

Ao visualizar como ocorre a configuração de um ambiente da indústria criativa, em especial sobre os Fab Labs, compreendemos que sua constituição é interdependente dos variados ambientes de mídia, o que influencia suas estruturas, movimentos socioeconômicos e sócio-organizacionais. De modo tipológico, estão situados na sociedade a partir de estruturas específicas dentro de um ecossistema inovativo, criativo, mas também, midiático.

Estão, portanto, o campo da comunicação e da mídia, mediando as formas organizacionais de cooperação, colaboração e compartilhamento, físico ou não, técnico ou amador, dos processos de inovação, tanto tecnológico, quanto social e midiático. Situação que demanda matrizes comunicacionais e relacionais diferenciadas para ser coerente com os interesses de seus públicos-usuários. Do mesmo modo, técnicas, instrumentos e profissionais precisam, talvez, elaborar diferentes perspectivas e usabilidades de sua prática para dar conta dos processos relacionais, mercadológicos, institucionais e administrativos de comunicação nesse tipo de ambiente da indústria criativa.

Dessa forma, percebemos que a comunicação se integra aos ambientes da indústria criativa por meio da midiatização, desdobradas pelas práticas de veiculação, vinculação e cognição defendidas por Sodré (2012), ao explicitar a emergência de um quarto bios existencial, o bios midiático.

\section{Referências}

ANDERSON, Chris. Makers: a nova Revolução Industrial. São Paulo: Elsevier Campus, 2012. 
BARICHELLO; Eugenia Mariano da Rocha et al. Estendendo as práticas de Relações Públicas sob a perspectiva teórica da ecologia das mídias. In: RUBLESCKI, Anelise; BARICHELLO, Eugenia Mariano da Rocha (Orgs.). Ecologia da Mídia. Santa Maria: FACOS-UFSM, 2013, p. 129-154.

BARICHELLO, Eugenia Mariano da Rocha; CARVALHO, Luciana Menezes. Entendendo as mídias sociais digitais a partir da ideia mcluhaniana de mediumambiência. MATRIZes. Ano 7, n. 1, p. 235-246, jan./jun. 2013. DOI: https://doi.org/10.11606/issn.1982-8160.v7i1p235-246

BARICHELLO, Eugenia Mariano da Rocha. A autoria na elaboração de uma Tese. In: MOURA, Claudia Peixoto; LOPES, Maria Immacolata Vassallo (Orgs.). Pesquisa em Comunicação: metodologias e práticas acadêmicas. Porto Alegre: EDIPUCRS, 2016, p.129-149.

BARICHELLO, Eugenia Mariano da Rocha . Visibilidade e Legitimidade na atual Ecologia da Mídia. Revista Estudos em Comunicação. n. 25, v. 2, p. 99-108, dez. 2017. Disponível em: http://ojs.labcom-ifp.ubi.pt/index.php/ec/article/view/306. Acesso em: 03 out. 2021.

CANAVILHAS, João. La radio en el ecosistema mediático del siglo XXI: estudio de caso en Portugal. Index.comunicación, v. 10, n. 3, p. 263-281, 2020. Disponível em: https://journals.sfu.ca/indexcomunicacion/index.php/indexcomunicacion/article/view/73 7. Acesso em: 03 out. 2021.

CASTELLS, Manuel. A Sociedade em Rede. 9. ed. Ver. Amp. São Paulo, 2016.

COULDRY, Nick; HEPP, Andreas. A construção mediada da realidade. São Leopoldo, RS: Ed. Unisinos, 2020.

DALL'AGNESE, Carolina Teixeira Weber; BARICHELLO, Eugenia Mariano da Rocha. Por uma abordagem ecológica e contextual da comunicação em tempos de midiatização profunda. Revista Culturas Midiáticas, Ano XI, n. 20, p. 1-16, jan./jun. 2018. DOI https://doi.org/10.22478/ufpb.1983-5930.2018v11n1.40708

EYCHENNE, Fabien; NEVES, Heloisa. FAB $\boldsymbol{L} \boldsymbol{A B}$ : a vanguarda da nova revolução industrial. São Paulo: Editorial FabLab Brasil, 2013.

FABFOUNDATION. Portal Institucional, c2021. Página inicial. Disponível em: http://www.fabfoundation.org. Acesso em: 03 out. 2021.

FABLAB-UNISINOSPOA. Portal Institucional, c2021. Página inicial. Disponível em: http://www.unisinos.br/fablab. Acesso em: 03 out. 2021.

FERNANDES, Fabio Frá; SILVA, Marcela Guimarães. Pesquisa, Desenvolvimento \& Inovação: Design Thinking como método e Comunicação Organizacional como estratégia. Brazilian Journal of Technology, Communication, and Cognitive Science, São Paulo, v. 8, n. 2, dez. 2020. Disponível em: http://www.revista.tecccog.net/index.php/revista tecccog/article/view/201. Acesso em: 03 out. 2021. 
FLORIDA, Richard. A Ascensão da Classe Criativa. Porto Alegre, RS: L\&PM, 2011.

GOMES, Pedro Gilberto. Dos meios à midiatização: um conceito em evolução. São Leopoldo, RS: Ed. Unisinos, 2017.

HJARVARD, Stig. A midiatização da cultura e da sociedade. São Leopoldo, RS: Ed. UNISINOS, 2014.

JACKSON, Katy. Make space for others. 2013. Disponível em: https://makingspaceforothers.com. Acesso em: 03 out. 2021.

LIFELAB. Portal institucional, c2021. Página inicial. Disponível em: http://www.ufrgs.br/lifee. Acesso em: 03 out. 2021.

MCLUHAN, Marshall. Os meios de comunicação como extensões do homem. São Paulo, SP: Cultrix, 1964.

MATOS, Guilherme Paraol de; TEIXEIRA, Clarissa Stefani. Análise sobre o sistema nacional de inovação no Brasil. REAVI - Revista Eletrônica do Alto Vale do Itajaí, v. 8, n. 13, p. 73-83, dez. 2019. DOI https://doi.org/10.5965/2316419008112019073

POALAB. Portal Institucional, c2021. Página inicial. Disponível em: https://www.poalab.net.br. Acesso em: 03 out. 2021.

POSTMAN, Neil. The Humanism of Media Ecology. Proceedings of the Media Ecology Association, v.1, p.10-16, 2000.

SILVEIRA, Ada Cristina Machado; SILVA, Marcela Guimarães e. Das garagens às cidades: espaços sociais para a indústria criativa. In: GUINDANI, Joel Felipe; SILVA, Marcela Guimarães e (Orgs.). Comunicação e Indústria Criativa: políticas, teorias e estratégias. Jaguarão, RS: CLAEC, 2018. p. 127-146.

SODRÉ, Muniz. Antropológica do Espelho: uma teoria da comunicação linear e em rede. 5. ed. Petrópolis, RS: Vozes, 2012.

STRATE, Lance; BRAGA, Adriana; LEVINSON, Paul. Introdução à ecologia das mídias. Rio de Janeiro: Ed.PUC-Rio, 2019.

TEIXEIRA, Clarissa Stefani et al. (Orgs.). Habitats de Inovação: alinhamento conceitual. Florianópolis: Perse, 2016.

TECNOPUC-FABLAB. Portal Institucional, c2021. Página Inicial. Disponível em: https://www.pucrs.br/ideia/fablab/. Acesso em: 03 out. 2021.

USINA FAB LAB. Portal Institucional, c2021. Página Inicial. Disponível em: http://www.usinafablab.com.br. Acesso em: 03 out. 2021. 
${ }^{\text {i }}$ Pós-doutoranda em Comunicação e Gestão de Indústria Criativas pela Faculdade de Letras da Universidade do Porto - Portugal. Professora do Programa de Pós-Graduação em Comunicação e Indústria Criativa (mestrado profissional) e do curso de Relações Públicas da Universidade Federal do Pampa - Unipampa, campus São Borja, RS - Brasil. Líder do GP Processos e Práticas nas Atividades Criativas e Culturais $(\mathrm{CNPq})$. Coordenadora do Observatório Missioneiro de Atividades Criativas e Culturais (OMiCult).

ii Doutorando no Programa de Pós-Graduação em Comunicação da Universidade Federal de Santa Maria (POSCOM / UFSM), Mestre no Programa de Pós-Graduação em Comunicação e Indústria Criativa (PPGCIC / Unipampa), Bacharel em Comunicação Social, Formada em Relações Públicas pela Universidade Cruz Alta (UNICRUZ), com especialização em Comunicação Empresarial pela Universidade Metodista de São Paulo (UMESP). Na linha de pesquisa "Estratégias de Mídia e Comunicação, ele estuda Comunicação Organizacional, Relações Públicas, Ambientes de Inovação e Ecossistemas à luz da Teoria da Ecologia da Mídia e da Mediatização. É membro do Grupo de Pesquisa em Comunicação Institucional e Organizacional (UFSM / CNPq) e GPAC - Grupo de Pesquisa em Processos e Práticas em Atividades Criativas e Culturais (Unipampa / CNPq). 